\title{
POPULATION, DIURNAL ACTIVITY PATTERNS AND FEEDING ECOLOGY OF THE INDIAN ROLLER CORACIAS BENGHALENSIS (LINNAEUS, 1758)
}

\author{
N. Sivakumaran ${ }^{1}$ and K. Thiyagesan ${ }^{2}$ \\ ${ }^{I}$ Bombay Natural History Society, Hornbill House, S.B. Singh Road, Mumbai, Maharashtra 400023, India. \\ ${ }^{2}$ Department of Zoology Division of Wildlife Biology, A.V.C. College, Mannampandal, Mayiladuthurai, Tamil Nadu 609305, India. \\ ${ }^{1}$ Email: vasikumaran@yahoo.com
}

\begin{abstract}
Population, diurnal activity pattern, roosting behaviour, and feeding ecology of the Indian Roller Coracias benghalensis (Linnaeus, 1758) was studied during January to March 1997 in the Mayiladuthurai and Sirkali taluks of Nagappattinam District, Tamil Nadu. Line transect surveys showed that the Indian Roller's density was high in agricultural habitat $\left(50\right.$ birds $\left.\mathrm{km}^{-2}\right)$, which suggested that they could play a role in controlling agricultural insect pests. Pellet analyses showed that insects were the principal food, which was also confirmed by focal observations. Studies on the diurnal activity pattern of the Indian Roller revealed that they feed mainly on ground insects. Their feeding activity was more in the evening hours, prior to roosting.
\end{abstract}

\section{Keywords}

Agro-ecosystem, Coracias benghalensis, foraging ecology, Indian Roller, population, Mayiladuthurai, roosting behaviour, Srikali

\section{Introduction}

Birds constitute an important component of agro-ecosystems and the role of birds in agro-ecosystems, is gaining more and more attention (Dhindsa \& Saini, 1994). As depredators of insects, birds stand supreme among vertebrates (Patel et al., 1987; Chakravarthy, 1988; Parasharya et al., 1988, 1994).

In many developing countries like India, agro-ecosystem is not completely modernised. The use of pesticides to control insect pests is avoided in certain areas, especially for low revenue crops like millet, maize, etc. (Parasharya et al., 1994). In such situations, birds become important bio-control agents, suppressing the insect pests. Therefore important predators like insectivorous birds need to be encouraged in the agroecosystem by use of appropriate management practices.
According to Dhindsa \& Saini (1994) research on the role of birds in the control of insect pests of agricultural areas are of top priority to our country.

The Indian Roller Coracias benghalensis (Linnaeus, 1758) is an insectivorous bird primarily found in agricultural areas. Ali and Ripley (1983) regarded the Indian Roller as highly beneficial to agriculture since it destroys vast quantities of insect pests. There is some amount of information on the general aspects of the Indian Roller (Lowther, 1944; Panicker, 1980; Rajasekar, 1982; Thiyagesan, 1991; Asokan, 1995). This study investigates the population, activity pattern, roosting behaviour and feeding ecology of the Indian Roller.

\section{Study area}

The study was carried out in the Mayiladuthurai and Sirkali taluks of Nagappattinam District, Tamil Nadu.

\section{Methods}

Population studies

Populations of Indian Roller were monitored in three habitats, agricultural, riverine and urban. The agricultural lands were under crops, such as paddy Oryza sativa, sugar cane Saccarum officinarum, groundnut Arachis hypogea and banana Musa paradisiaca. The riverine habitat was the area along the course of the River "Cauvery". Urban habitat was in areas with a predominance of human dwellings. Line transects (Burnham, et al., 1980) of $2 \mathrm{~km}$ length were laid in the three habitat types. Census was carried out immediately after sunrise, between 0600 and $0800 \mathrm{hrs}$. Double counting was avoided by noting the direction and movements of birds. The censuses were done at the rate of 0.75 to $1.00 \mathrm{~km} \mathrm{hr}^{-1}$ and counting was avoided on cloudy, rainy and windy days. For each bird sighting, number of birds, and perpendicular distance from the transects were recorded. From the data so obtained the density of the bird was calculated by using the following formula 


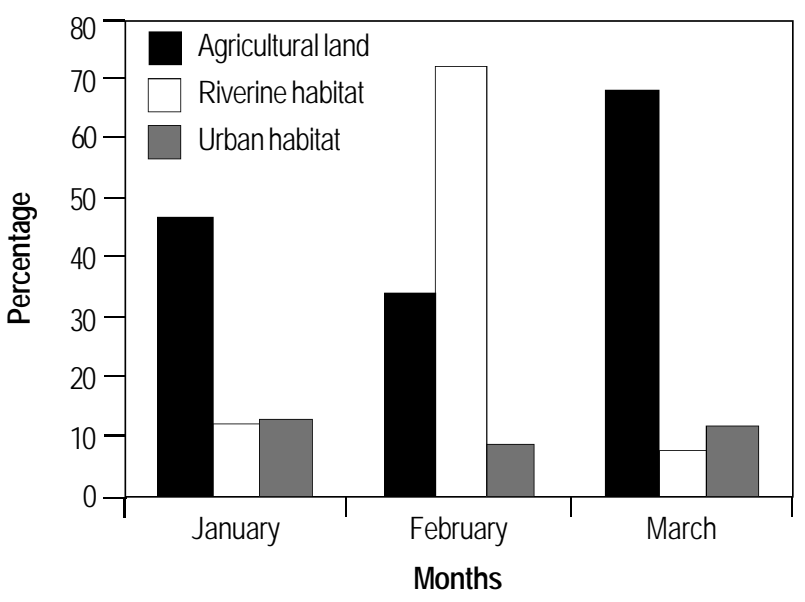

Figure 1. Month-wise variations in the percentage of Indian Roller Coracias benghalensis at three habitat types in the study area

Number of birds seen

Density $($ No./sq km) $=$

$$
2 \times \mathrm{LxW}
$$

Where, $\mathrm{L}=$ Length of the transect and $\mathrm{W}=$ Mean perpendicular distance

\section{Time activity budget}

Daily time activity budget of the Indian Roller was studied by focal animal sampling method (Altmann, 1974). Observations were made in four different time blocks of a day viz., 0600-0900hr, 0900-1200hr, 1200-1500hr and 1500-1800hr and the activities of birds were recorded. The data was converted into percentage time spent for each activity (Hutto, 1990).

\section{Roosting behaviour}

The roosting behaviour was studied from three roosting sites of Indian Roller. The roosting and awakening time of the bird, and also the pre-roosting and post-awakening behaviour of these three individuals were recorded.

\section{Diet/foods}

The pellets of Indian Roller were collected from under their perches and/nesting sites. A total of 638 pellets were collected from four sites. Collected pellets were dried to constant weight by keeping them at $60^{\circ} \mathrm{C}$ in a hot air oven. The pellets were then dissolved in water and $5 \% \mathrm{NaOH}$ to isolate the hard prey remains. To dissolve the pellets, a quantity of dissolvent was used depending on the pellet size. The prey items were identified by comparing with the museum specimens collected from the study areas.

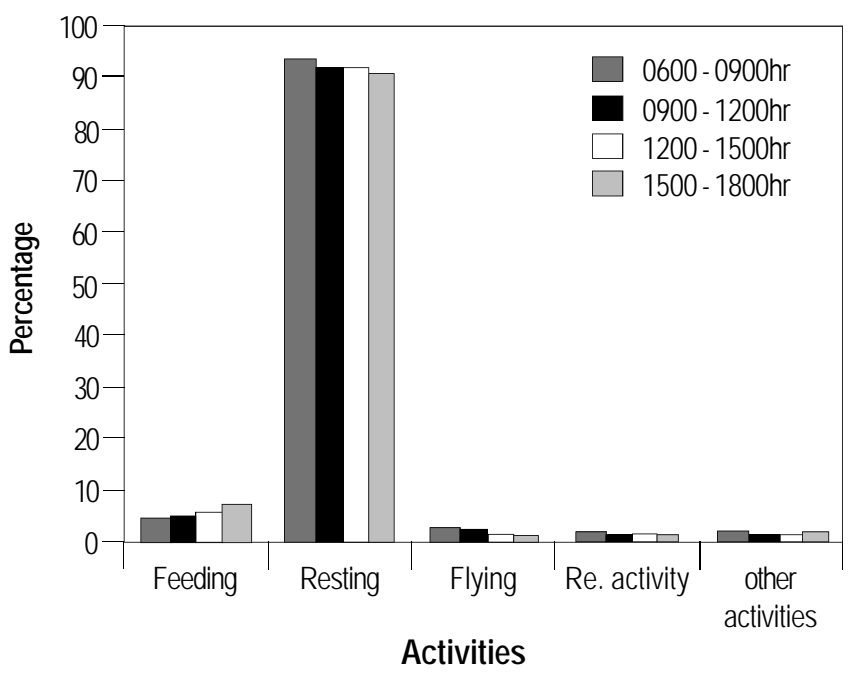

Figure 2. Time activity budget (per cent time spent) of Indian RoIlerCoracias benghalensis in the study area.

The foraging behaviour of the Indian Roller with respect to its perch characteristics and feeding substrate types were studied. The perch types of the Indian Roller were categorized as electric wires/telegraphic wires, walls, trees, shrubs and 'others', which included sticks and mounds above the ground level. The different perch and foraging heights were grouped as 0-3m, 3$6 \mathrm{~m}, 6-9 \mathrm{~m}, 9-12 \mathrm{~m}$, and $12-15 \mathrm{~m}$ and their percent use was calculated by using Bell \& Ford (1990) method.

\section{Foraging substrate and position}

The foraging substrate of the Indian Roller were classified into i) air, ii) plants and iii) ground, and for each case the percentage use was estimated, the percentage use of above plant categories was estimated. The use of various positions on trees for insect feeding was classified as canopy, trunk and base and the percentage use of each category was also calculated.

\section{Feeding techniques}

The foraging strategies of the Indian Roller were classified into 1) hawking: a flight, which resulted in the capture of a flying insect; 2) gleaning: a standing or moving bird picking a stationary prey item from a substrate; and 3) ground feeding: the capture of insects and mites from the ground surface.

\section{Observation and Results}

Results of the population studies on the Indian Roller at the three habitat types during different months of the study period are shown in Fig. 1. In January and March the Indian Rollers were more in numbers in agricultural lands and during February in riverine habitats. 


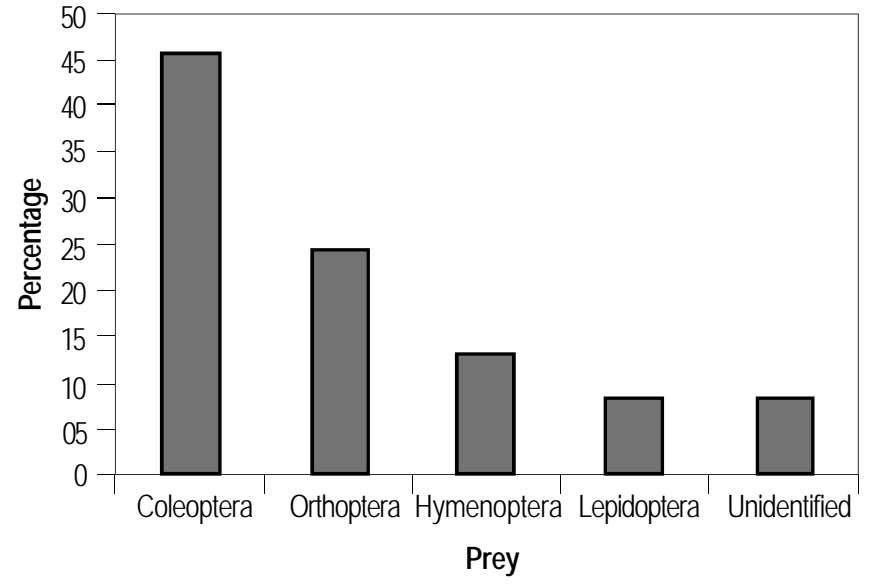

Figure 3. Prey composition (\%) of pellets of Indian Roller Coracias benghalensis

\section{Time activity budget}

Diurnal activity patterns of the Indian Roller during different time blocks of a day during the study period are shown in Fig. 2. Totally 216 hours were spent in recording the Indian Roller's activity pattern. Overall the Indian Roller spent most of its time resting $(87.1 \%)$ i.e., sitting. Feeding $(5.5 \%)$ came next in the order of preference which was followed by flying (5.7\%), reproductive activity $(0.7 \%)$ and other activities $(1.0 \%)$.

\section{Roosting behaviour}

The Indian Roller at the study area began roosting between 1845 and $1849 \mathrm{hr}$ and their awaking time was between 0558 and

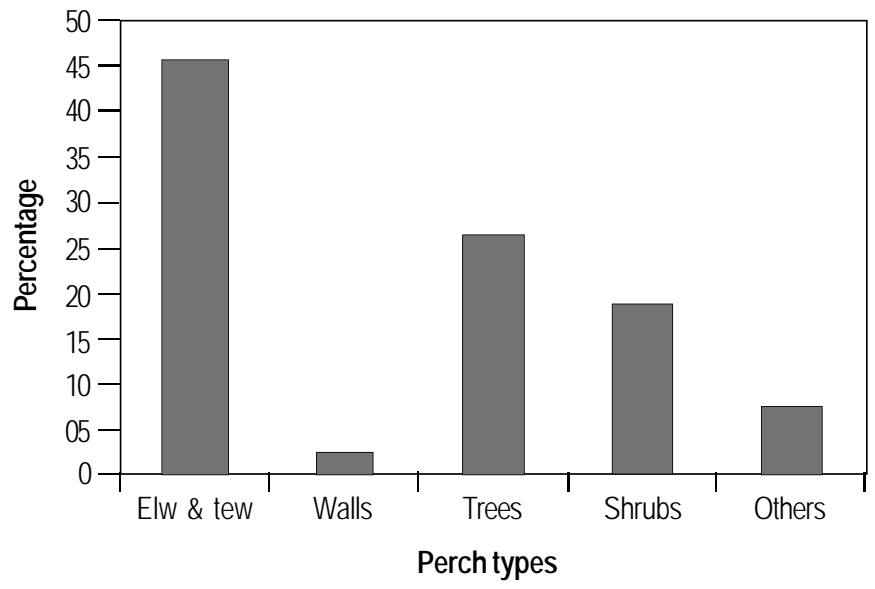

Figure 4. Percent use of differenct perch types by Indian Roller Coracias benghalensis

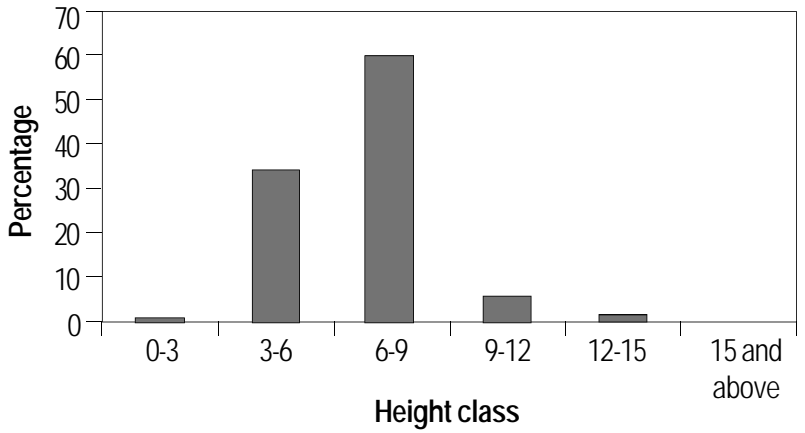

Figure 5. Percent use of different height $(m)$ classes of perch and perching for insect feeding by the Indian Roller Coracias benghalensis

0605hr. Immediately after awaking in the morning the birds spent a few minutes preening and flew around their roosting sites and perched for few minutes before they flew away for their daily routine. Prior to roosting they invariably had an evening bout of feeding and a few minutes of comfort activities like preening.

\section{Feeding ecology}

Pellet analysis

Results of pellet analysis are shown in Fig. 3. Totally 638 pellets, 154 from site "A", 157 from site "B", 162 from site "C" and 165 from site " $\mathrm{D}$ " were analysed. Coleopteran beetles were the predominant prey items as they constituted from $38.3 \%$ to $52.7 \%$ of the prey ranging in different sites with an overall value of $45.7 \%$ (Fig. 3). Overall, this was followed by Orthopteran remains (24.5\%), Hymenopterans (13.0\%), Lepidopterans (8.5\%) and unidentified (8.3\%).

\section{Foraging behaviour}

Electric or telegraphic wires were their main perches $(45.45 \%)$ followed by trees (26.44\%) and shrubs (18.56\%) (Fig. 4). The Indian Roller mainly used perches of height ranging from $3.9 \mathrm{~m}$ for locating insect prey (Fig. 5) and even in higher perches their preferred perching heights were $3-9 \mathrm{~m}$. All the insect prey was captured below $3 \mathrm{~m}$ from the ground level. The Indian Roller obtained its insect food predominantly from the ground (97.43\%) (Fig. 6). Whenever the Indian Roller fed on insects from trees, it invariably obtained them from the canopies. Ground feeding was the predominant foraging method used by the Indian Roller (Fig. 7). 


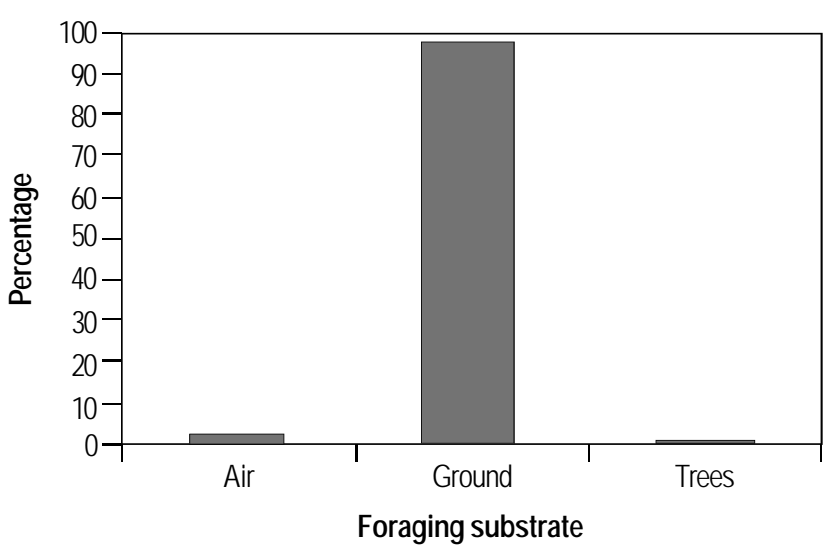

Figure 6. Percent insect capture from the three foraging substrate categories by the Indian Roller

\section{Discussion}

The studies showed that the Indian Roller preferred agricultural lands (Fig. 1), as possibly due to relatively rich supply of insects. Food is frequently the most important density dependent factor for birds (Lack, 1966). The riverine habitats ranked first in the order of preference to the Indian Roller during February 1997. This might be due to the harvesting of paddy and drastic reduction of availability of prey at agricultural lands and greater vegetation density at the riverine habitats, a strong association between the measures of tree cover and insectivorous bird densities (De Graaf \& Wentworth, 1986). The tree covers were important factors in the Indian Roller's habitat selection during harvesting and cultivation in this study area. This might be the reason more number of birds had been recorded in the riverine habitat during the month of February. Human habitations ranked as third in order of preference of Indian Roller due to habitat disturbances and lack of food availability. However, future studies covering insect availabilities simultaneously should be undertaken to understand the bird's habitat selection.

Time activity studies showed that the Indian Roller fed more during the late evening. Since they are mainly sit-and-wait predators, they spent majority of their time sitting (resting). The activity pattern in birds can be influenced by various factors such as habitat and season (Ford et al., 1990; Asokan, 1995), food availability (Hutto, 1990), etc. Both, the relationships between the above factors and the time activity pattern of the Indian Roller are needed to understand its behaviour fully.

Studies on the roosting behaviour of the Indian Roller have shown the Indian Roller to come in late to roost after an invariably late evening feeding bout. This showed that the Indian Roller plays an important role in the control of insects pests. If one

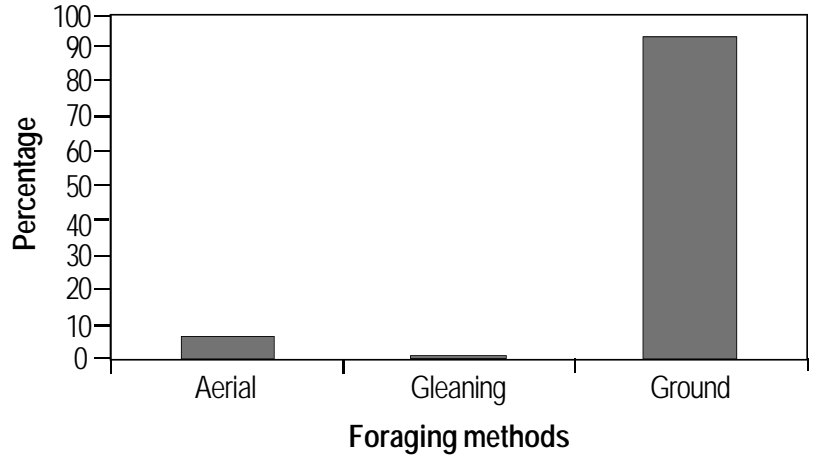

Figure 7. Percent use of different foraging methods for insect feeding by the Indian Roller Coracias benghalensis

could make a checklist of insects active during evening hours and their role in agriculture, then the bird's role could be fully understood. Dhindsa \& Saini (1994) also regarded that not much is known about the roosting ecology of Indian birds which this study tries to fulfill to some extent.

Pellet analysis inferred that Coleopterans were the principal food of the Indian Roller. Further, insect body parts constituted almost $100 \%$ of the prey remains in the pellets of Indian Roller, an indication that it could be a very potent insect control agent. Parasharya et al. (1994) also recorded the Indian Roller to be an important bio-control agent against the White Grub (Holotricha sp. scarabidae) which is an important subterranean pest damaging root system of several crops. However, in the present study the exact insect species on which the Indian Roller fed could not be ascertained fully.

Behavioural studies have clearly shown that the Indian Roller is principally a ground feeder, and rarely feeds in air (Ali \& Ripley, 1983; Asokan, 1995).

\section{Acknowledgements}

I would like to acknowledge Dr. K. Thiyagesan, Reader in Zoology for guidance and valuable suggestion towards the successful completion of this investigation and Dr. R. Kanakasabai Professor and Head, Department of Zoology, Division of Wildlife Biology for his encouragement and facilities. I thank Dr. Ranjit Manakadan, Senior Scientist, BNHS for his immense help and valuable suggestions towards completion of this work.

\section{References}

Ali, S. (1996). The book of Indian Birds. Bombay Natural History Society, Bombay.

Ali, S. and S.D. Ripley (1983). The Handbook of the Birds of India and Pakistan. Oxford University Press, London. 
Altmann, J. (1974). Observational study of behaviour: sampling methods. Behaviour 49: 227-267.

Asokan, S. (1995). Ecology of the small Green Bee-eater, Merops orientalis Latham 1801 with special reference to its population, feeding and breeding in Mayiladuthurai, Tamil Nadu, South India. Ph.D. Thesis, Bharathidasan University, Thiruchirappalli (unpublished).

Bell, H.L. and H.A. Ford (1990). The influence of food shortage on interspecific nich overlap and foraging behaviour of three species of Australian Warblers (Acanthizidae). Studies in Avian Biology 13: 381388.

Burnham, K.P., D.R. Anderson and J.L. Laake (1980). Estimation of the density from line transect sampling of biological population. Wildlife Monographs No. 72-202p.

Chakravarthy, A.K. (1988). Bird predators of poel borers of field bean (Lablab Niger Medick). Tropical Pest Management 34: 395-398.

DeGraaf, R.M. and J.M. Wentworth (1986). Avian guild structure and habitat associations in suburban bird communities. Urban Ecology 9: 399-412.

Dhindsa, M.S. and H.K. Saini (1994). Agricultural Ornithology, an Indian prespective. Jounal of Biological Science 19(4): 391-402.

Ford, H., A.L. Huddy and H.Bell (1990). Seasonal changes in foraging behaviour of three passerines in Australian eucalyptus. Woodland Studies in Avian Biology 13: 245-253.

Hutto,R.L. (1990). Measuring the availability of food resources studies. Avian Biology 13: 20-28.

Lack, D. (1966). Population Studies of Birds. Oxford University Press, London.
Lowther, E.H.N. (1944). Notes on some Indian Birds. Journal of the Bombay Natural History Society 40: 409-424.

Panicker, K.N. (1980). Ecology of hole nesting birds. Journal of the Bombay Natural History Society 75: 1227-1237.

Parasharya, B.M., J.F. Dodia, D.N. Yadav and R.C. Patel (1988). Effect of bird predation and egg paressitism on caster semilooper Achaca janata Linn. (Lepidoptera: Noctuidae) in Gujarat. Journal of Biological Conservation 2: 80-82.

Parasharya, B.M., J.F. Dodia, K.L. Mathew and D.N. Yadav (1994). Natural regulation of white grub (Holotrichia sp. scaralidae) by birds in agroecosystem. Jouranl of Biosciences 19(4): 381-390.

Patel, H.M., D.N. Yadav, B.M. Parasharya and R.C. Patel (1987). A note on predation of Catopsilla sp. (Lepidoptera: Pieridae) by birds and wasp. Journal of the Bombay Natural History Society 84: 452-454. Rajasekar, R. (1982). Studies on the avian nests and eggs of Mannampandal area. M.Sc. Dissertation. A.V.C. College, University of Madras (unpublished).

Thiyagesan, K. (1991). Ecology of cavity nesting birds in and around Mayiladuthurai, Tamil Nadu, South India. Ph.D. Thesis. Bharathidasan University, Thiruchirappalli (unpublished).

Titman, R.D. (1981). A time activity budget for breeding Mallards (Anas platyrhynchos) in Manitoba. Canadian Field Naturalist 95: 266271.

Verner, J. (1965). Time budget of the male long billed marsh-wren during breeding season. Condor 67: 125-139. 